\title{
Guía de capacitación para la creación de una caja común en el barrio Celen de la parroquia Gualel del cantón Loja
}

\section{Training guide for the creation of a common box in the Celen neighborhood of the Gualel parish of the Loja canton}

Enma Marlene Paccha Márquez

Universidad Internacional del Ecuador, Ecuador

Autor para correspondencia: enpacchama@uide.edu.ec

Fecha de recepción: 20 de julio de 2018 - Fecha de aceptación: 30 de agosto de 2018

Resumen: La presente investigación se desarrolló en el barrio Celen de la Parroquia Gualel del cantón Loja, en los sectores productivos de actividades agrícolas (agricultura y ganadería), en la cual se evidencio una inadecuada administración de los recursos económicos, según información proporcionada por los moradores del sector, ante esta problemática se planteó la creación de una caja común que propicie el Ahorro - Inversión, e incentive la generación de actividades productivas, que aporten superar la precariedad en la que en algunos casos afecta a estas comunidades. Para el desarrollo del trabajo se utilizó la investigación cualitativa, empleando la técnica de la observación, la entrevista y la información bibliográfica. Como resultado de la propuesta se presenta la Guía de capacitación en educación financiera, para la población participante, orientada a administrar los recursos económicos - financieros constituyéndose en una herramienta útil que beneficie a propios y extraños y potencie sus actividades agrícolas productivas que es la razón de ser de la comunidad. Se concluye la importancia de vincularnos con la sociedad a través academia para la capacitación de sectores vulnerables como es el caso del barrio Celen mediante la capacitación impartida que permitió la conformación de una caja común llamada Espíritu Santo de Celen, la misma receptara ahorros de la comunidad y préstamos a los socios y sus familiares que requieran de estos servicios así como un abastecimiento permanente de recursos monetarios orientados a una producción constante y la generación de ingresos a corto plazo.

Palabras Claves: caja; caja común; ahorro; precariedad

Abstract: The present investigation was developed in the neighborhood Celen of the Gualel Parish of the Loja canton, in the productive sectors of agricultural activities (agriculture and livestock), which evidenced an inadequate administration of the economic resources, according to information provided by the inhabitants of the sector, before this problem was raised the creation of a common fund that encourages Savings - Investment, and encourages the generation of productive activities, which contribute to overcome the precariousness in which in some cases affects these communities. For the development of the work qualitative research was used, using the technique of observation, interview and bibliographic information. As a result of the proposal, the Financial Education Training Guide for the participating population is presented, aimed at administering the economic and financial resources, becoming a useful tool that benefits both the individual and the foreigners and enhances their productive agricultural activities. be from the community. It concludes the importance of linking with society through academia for the training 
of vulnerable sectors such as the Celen neighborhood through the training provided that allowed the formation of a common box called Holy Spirit of Celen, the same receptara savings community and loans to members and their families that require these services as well as a permanent supply of monetary resources aimed at constant production and the generation of short-term income.

Key Words: caja; caja común; savings; precariedad

\section{Introducción}

La guía de capacitación respalda lo que promueve la constitución de la república del Ecuador; que entre sus objetivos está apoyar actividades que impulsen el buen vivir especialmente de los sectores menos favorecidos de la economía nacional siendo importante para ello contar con programas de capacitación activa en temas de educación financiera para el correcto manejo de sus recursos provenientes de las actividades productivas.

La guía de capacitación comprende elementos necesarios, para lograr que las personas, de los sectores vulnerables de la ciudad de Loja y especialmente del Barrio Celen se familiaricen con términos como préstamo, ahorro - inversión y se sientan parte de la capacitación logrando una identidad propia sobre el tema, que permita el intercambio de criterios entre los participantes, como un medio para fortalecer los conocimientos financieros entre los participantes.

La capacitación se realizará en 16 semanas, se realizará taller en los que se insertará estrategias de educación para adultos; así mismo es importante señalar la importancia de una caja común, considerada como un modelo de operación en la que busca organizar las trasferencias de dinero de los habitantes de una comunidad y distribuir de una forma equitativa los ingresos percibidos como consecuencia de las actividades de ahorro, prestamos e inversiones el sistema de manejo es como de una cuenta única, en donde los recursos monetarios de una actividad productiva se manejan como recursos únicos.

En el caso de la comunidad de Celen se pretende que los recursos recaudados producto de la comercialización de la producción agrícola, sean depositados en la caja, para que se puedan generar excedentes e incentivar el ahorro que ha futuro se vean revertidos en préstamos en beneficio de la propia comunidad, con fines de mejora en sus condiciones de vida y al mismo tiempo de la comunidad en general. Aportarle bases económico-financieras y de género que permitan construir relaciones sociales horizontales y equitativas, así como mejores condiciones económicas.

\section{Problema o argumento}

La problemática general que atraviesa el país, afecta de manera significa a las provincias fronterizas, en el caso de la provincia de Loja, los índices de pobreza son cada vez mayores, en donde los más afectados son los habitantes de las zonas urbano marginales de la ciudad y provincia. Según (Miró Acedo \& Fernández Montes, 2016) “El conjunto de organizaciones y prácticas socioeconómicas no incluidas ni en el sector privado lucrativo, ni en el sector público se ha denominado economía popular y solidaria o economía del trabajo" (Flores \& Rello, Capital Social Rural, 2002); por lo indicado de acuerdo a las exigencias de los organismos de control a las Instituciones de Educación Superior, la Universidad Internacional del Ecuador en este 
contexto y dando cumplimiento a esta disposición ha querido aportar a estos sectores con la guía de capacitación para la creación de una caja Común en el Barrio Celen de la Parroquia Gualel del cantón Loja.

\section{Revisión de la literatura}

Cajas rurales de Ahorro y Crédito, Según Flores y Rello en la década de los noventa aparecieron en Honduras una serie de financiamientos rurales alternativos como los bancos comunales las cajas de Ahorro y crédito rurales, cuyo común denominados ha sido manejar el crédito con una tendencia de la privatización de los servicios, para el sector rural y el bienestar de las familias campesinas.

Principios del cooperativismo

Según (Gaminde, 2017, pág. 142). "El cooperativismo es la doctrina cooperativa de donde se desprende los principios y valores cooperativos, en condiciones de igualdad a la persona que acepte su responsabilidad y respete sus postulados".

Características de una caja común

(Salgado, pág. 94). "Dice que las uniones de crédito, son asociaciones auxiliares de crédito, constituida de acuerdo con la legislación mercantil”.

(Flores \& Rello, Capital Social Rural, 2002, pág. 102) “Manifiestan que en ciudad de Honduras en la década de los noventa apareció una serie de modalidades de financiamiento Rural alternativo, como bancos comunales y de sistemas de financiamiento autogestionario". Por lo indicado las Cajas comunes, no tienen filiación política ni religiosa: son el esfuerzo de vecinos por contar con dinero en efectivo de sus propios ahorros que, a su vez, se dan como préstamos y que, luego, pueden ser invertidos en actividades productivas ser un instrumento económico comunitario auto sostenible que busca ir generando confianza, tejido y capital social; siendo también, espacios donde aprender y desarrollar habilidades de participación ciudadana.

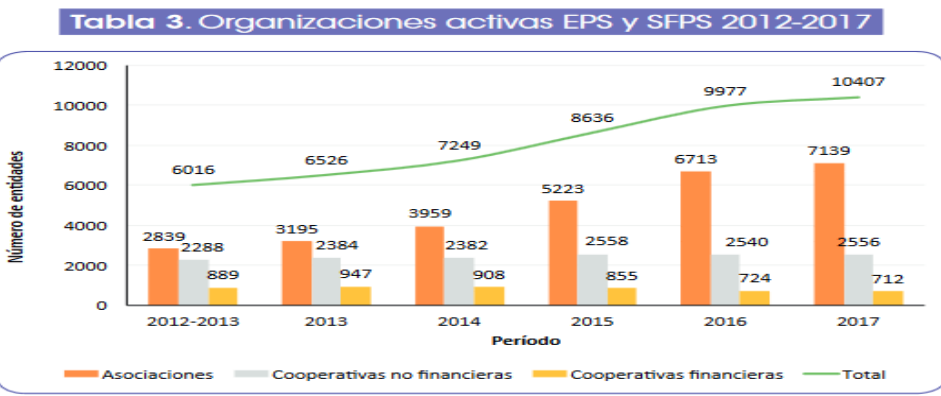

Fuente: Superintendencia de Economía Popular y Solidaria. Boletín SEPS. Ecuador popular y solidario 2017

En donde se evidencia el apoyo recibido por parte de las organizaciones sociales a las actividades productivas que estas emprenden, en los diferentes sectores del territorio nacional. (Boletin SEPS , 2017)“Mismas que se han incrementado desde el año 2012, de 6.016 a 10.407 organizaciones, hasta febrero de 2017”. 
Así mismo ha sido importante tomar en cuenta a las organizaciones que han sido capacitadas, por parte de estudiantes, con fines de mejorar sus actividades productivas; como se evidencia en el cuadro adjunto.

\begin{tabular}{|c|c|c|c|c|c|c|c|c|c|c|c|c|}
\hline \multirow[b]{3}{*}{$\frac{\bar{\Phi}}{z}$} & \multicolumn{2}{|c|}{2012} & \multicolumn{2}{|c|}{2013} & \multicolumn{2}{|c|}{2014} & \multicolumn{2}{|c|}{2015} & \multicolumn{2}{|c|}{2016} & \multicolumn{2}{|c|}{ TOTAL GENERAL } \\
\hline & \multicolumn{12}{|c|}{ Número } \\
\hline & 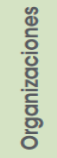 & 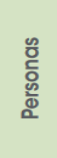 & 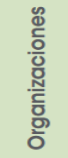 & $\begin{array}{l}\text { : } \\
\text { č } \\
\text { o. } \\
\text { o. }\end{array}$ & 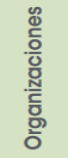 & 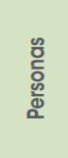 & 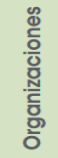 & 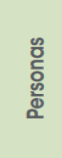 & 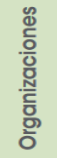 & 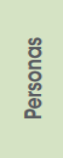 & 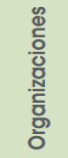 & 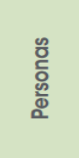 \\
\hline 1 & 254 & 606 & 999 & 2988 & 951 & 1928 & 489 & 2804 & 199 & 2151 & 2892 & 10477 \\
\hline 2 & 33 & 94 & 150 & 450 & 124 & 314 & 85 & 1236 & 54 & 890 & 446 & 2984 \\
\hline Asoc. & 53 & 176 & 243 & 621 & 243 & 619 & 85 & 240 & 187 & 374 & 811 & 2030 \\
\hline TOTAL & 340 & 876 & 1392 & 4059 & 1318 & 2861 & 659 & 4280 & 440 & 3415 & 4149 & 15491 \\
\hline
\end{tabular}

Fuente: Superintendencia de Economía Popular y Solidaria. Boletín SEPS. Ecuador popular y solidario 2017. Elaboración: Dirección Nacional de Investigación y capacitación.

(Morales B. R., 2015, pág. 102) El poder que existe en el ser humanos cuando se da cuenta que todo depende el mismo. Por esta razón el presente trabajo intenta guiar en el proceso de formación de Cajas Urbanas impulsando, de forma paralela, la capacitación individual y comunitario-grupal (incluyendo a las mujeres, los jóvenes y a otras poblaciones en situación de vulnerabilidad), así como su vinculación con propuestas de empoderamiento que apunten hacia la equidad y la igualdad para poner en valor las experiencias, los conocimientos y las inquietudes de las personas participantes de las Cajas

Según el diccionario financiero Cuida tú futuro. "Una caja común es aquella que permite una mayor eficiencia en la prestación de un servicio financiero, lo cual genera un gran número de ventajas, entre las se encuentran":

- Ahorrar dinero

- Contar con préstamos

- Tener un respaldo financiero

\section{Quienes pueden participar en una caja común}

(Oriol, 2011), pueden participar hombres y mujeres que sean mayores de edad, no se requiere condición social o económica, pueden participar desde jóvenes, hasta su edad mayor, sin importar su etnia, idioma o religión, amas de casa, siendo la única condición que aporten económicamente a sus hogares. El objetivo es brindar igualdad de oportunidades para elevar el nivel de vida de las personas.

\section{¿Qué debo considerar antes de integrar una caja?}

Antes de conformar una caja debo considerar, que las personas realicen actividades comunes y tengan necesidades comunes, sin embargo será necesario entender sus tiempos disponibles, porque existen casos en los que trabajan en otras comunidades y capacitaciones y se encargan del cuidado a niños pequeños a enfermos o a adultos mayores, aún existe comunidades con un machismo bien marcado en el que las mujeres no pueden participar de temas de 
capacitación para coordinar las reuniones de los grupos de trabajo, cabe considerar que el trabajo tanto con hombre y con mujeres tienen ciertas diferencias.

\section{¿Qué necesito para formar una Caja?}

(CEPAL, 2011) Se necesita contar con personas comprometidas, para que la capacitación consiga los logros esperados es necesario que quienes participan tenga intereses comunes; de esta manera se lograría lo que se espera que todos estén satisfechos. Es fundamental contar con personas que se pueda confiar, para que asuman los compromisos adquiridos y cumplan con las responsabilidades de la organización.

Es necesario hacerles llenar un test personal a cada participante, para conocer de cerca algunas situaciones personales que pueda dificultar su participación de todos los que forman parte de la organización en cada una de las reuniones. Se puede empezar con un grupo minoritario de participantes, pero comprometidas. El sistema se realizará con la presentación de varias solicitudes en conjunto y que buscan los mismos intereses es la clave para lograrlo. Es importante asignarle un nombre a la caja, se puede hacer por votación (Gutierrez Fernandez, 2013)¿Qué necesito para formar una Caja?

1. Conocimiento de las operaciones básicas (Sumar, estar, multiplicar y dividir, sacar tasas de interés)

2. Conocimiento de la tasa de interés, inversiones, saldo y eficiencia

3. Cuentas, cálculo de intereses, registro y seguimiento de préstamos

4. Total, de dinero que cada persona ahorra y los intereses ganados.

5. Control detallado de las salidas de dinero, retiro de dinero, préstamos y gastos de papelería (compra de materiales, implementos de oficina).

Debe existir claridad y transparencia en el manejo de los dineros.

Llevar libros de entradas y salidas.

\begin{tabular}{cccccc}
\hline Fecha & Concepto & Comprobante & Entrada & Salida & Saldo \\
\hline 06-06-2017 & Depósito de Ahorros & 00045 & 300,00 & - & 300,00
\end{tabular}

Elaboración: La Autora

Según la guía de creación de cajas urbanas (Renteria \& Alberto, 2014). Al crear una Caja de Ahorro y Crédito Comunitaria también es necesario dar respuesta a las siguientes interrogantes:

- ¿Cuál es el interés común que se tiene para formar la Caja? ¿Existe alguna necesidad Común que resolver?

- ¿Qué actividades se definirán a partir del objetivo?

- ¿Se cobrará alguna cuota por concepto de papeleo?

- Definir las obligaciones y los derechos que supone ser parte de la Caja.

- ¿Qué sucede si alguien no asiste a las reuniones? ¿Se le cobra una multa? 
- ¿A cuántas reuniones puede faltar?

- ¿Puede enviar a un representante en su lugar?

- ¿Qué beneficios se tienen por ser parte de la Caja?

Definir el tipo de personas (hombres y mujeres) que pueden ser parte de la Caja, quienes deben comprender su doble papel como "propietarias" y "clientas".

a. ¿Quién puede ser socio?

b. ¿Cuáles son los requisitos para serlo?

c. ¿Cuándo se deja de ser socio?

d. ¿Comprenden y comparten las reglas que gobiernan la Caja?

e. ¿Comprenden y conocen sus derechos, responsabilidades y beneficios?

f. ¿Pueden transferirse los derechos como socio, al cónyuge, hijo u otro familiar?

g. ¿Qué beneficios se tienen por ser socio?

Reglamento interno caja común

Junta directiva

Presidente.

Secretario

Tesorero.

Vocal 1

Vocal 2

Normativa de la Caja Comunitaria del Barrio Celen de la parroquia Gualel del cantón Loja.

La caja comunitaria Espíritu Santo del Barrio Celen, en uso de las atribuciones que le confiere el literal 3 del Art.62 del Estatuto en vigencia emite la normativa de la Caja de Ahorro y Crédito. Según resolución $\mathrm{N}^{\circ} 436$ - 2018-F y la junta política de regulación monetaria y financiera en el artículo 163 determina otras formas de conformación de entidades asociativas y comunitarias como la conformación de cajas comunes.

\section{Título I}

De sus fines y objetivos

Art. 1. Son fines y objetivos de la Caja de Ahorro y Crédito Comunitaria:

a. Fomentar el espíritu de ahorro y de mutua ayuda entre los miembros de la Asociación Comunitaria del Barrio celen.

b. Otorgar préstamos a sus socios, de conformidad con el presente Reglamento.

\section{Título II}

De los socios

Art. 2. Son miembros de la Caja de Ahorro y crédito, todos los socios que integran la La sociedad comunitaria

Art. 3. Los miembros de la Caja de Ahorro y Crédito comunitaria Espíritu Santo del barrio Celen de la parroquia Gualel del cantón Loja, tendrán los siguientes derechos y obligaciones: 
a. Derecho al crédito.

b.Participación en utilidades.

c. Acatar las disposiciones de este Reglamento.

d. Cumplir las resoluciones de la Comisión de Crédito.

e. Pagar de forma oportuna sus obligaciones económicas; aportaciones fijadas por este Reglamento, cuotas por crédito y cualquier otro que creare el organismo competente y fuere aprobado por la Asamblea. causales:

Art. 4. La calidad de socio de la Caja de Ahorro y Crédito se perderá por las siguientes

a. Retiro voluntario de la Caja, mediante solicitud escrita desafiliación, dirigida al Presidente de la Caja.

b.Por fuerza mayor.

c. Por causales de acuerdo al Art. xxxx del Estatuto de la Asociación.

d. Por fallecimiento.

Art. 5. En cualquiera de estos casos, los derechos del socio serán liquidados, de conformidad con la Ley y el presente Reglamento.

Art. 6. La liquidación de los derechos del socio fallecido será realizada en favor de los beneficiarios declarados por él mismo, de conformidad con el Código Civil en la parte pertinente.

\section{Título III}

Del capital

Art. 7. El Capital de la caja de Ahorro y Crédito estará constituido por:

a. Las aportaciones mensuales de sus socios, equivalentes a \$5,00 como obligatorio; más no según la voluntad del socio. Cantidades que serán depositadas mensualmente, semanalmente o quincenalmente con el pago del aporte de agua de la comunidad.

b.Los intereses percibidos por el capital en giro serán del $1 \%$.

c. Otras cuotas que fijare el Organismo Directivo.

\section{Título IV}

Del régimen administrativo

Art. 8. La administración de la Caja de Ahorro y Crédito estará bajo la responsabilidad de la directiva de la Caja. Este organismo estará integrado por el Presidente de la caja comunitaria Espíritu Santo de la comunidad de Celen, quien lo presidirá; tres Vocales con sus respectivos Suplentes, integrada por el secretario, tesorero y el responsable de asuntos sociales, designados conjuntamente, de conformidad con lo establecido en el Normativa de Elecciones de la Asociación de aguas.

Art. 9. La Secretaria de la comisión Ejecutiva de Crédito será desempeñada por el presidente de la Caja.

Art. 10. La Comisión Ejecutiva de Crédito se reunirá ordinariamente, cada 30 días; y, de manera extraordinaria, cuando la convoque el Presidente, o por petición de los Vocales. 
Art. 11. Son funciones y atribuciones de la Comisión Ejecutiva de Crédito:

a. Aprobar las solicitudes de crédito.

b. Dirigir y Administrar la Caja de Ahorro y Crédito.

c. Cumplir y hacer cumplir el presente Reglamento.

d. Fijar el interés de las operaciones crediticias.

e. Ordenar la ejecución judicial de las obligaciones económicas vencidas de los socios.

f. Contratar los servicios profesionales, para llevar la contabilidad de la Caja de Ahorro y Crédito.

g. Fijar los honorarios del Gerente y el monto de su caución; así como el costo de los servicios de contabilidad.

h. Ordenar y aprobar la adquisición de material de escritorio, útiles y enseres indispensables para el normal funcionamiento de la Caja.

i. Resolver las cuestiones no estipuladas en este Reglamento.

Art. 12 El presidente es el encargado de la administración y custodia de los fondos de la Caja y el ejecutor de las resoluciones de la Comisión.

Art. 13. Para ser presidente se requiere ser miembro de la Asociación de Desarrollo Comunitario Espíritu Santo de la comunidad de Celen, por un tiempo no menor a cuatro años. Además, deberá tener un nivel mínimo de instrucción a la función a desempeñar, así como experiencia para el cargo mínimo de dos años en funciones similares.

Art. 14. La persona designada como presidente presentará una caución, cuyo monto será determinado por la Comisión Ejecutiva de Crédito.

Art. 15. Son atribuciones y deberes del Presidente:

a. Llevar el registro de ahorros, intereses, préstamos, abonos y otros ingresos y egresos en forma individual, en base a cualquier sistema de archivo.

b. Legalizar conjuntamente con la firma del Presidente todos los documentos concernientes con el funcionamiento de la Caja.

c. Responder pecuniariamente de los fondos de la Caja.

d. Rendir los informes que le solicitare la Comisión Ejecutiva de Crédito.

e. Vigilar la elaboración de la contabilidad de la Caja.

f. Presentar el informe semestral del movimiento administrativo-contable del organismo, tanto a la Comisión Ejecutiva de Crédito como a la Asamblea General de la Asociación de Desarrollo Comunitario Namanda, según lo dispone el Estatuto de la misma, en el Art. xxx

\section{Título V}

De las operaciones

Art. 16. La Caja de Ahorro y Crédito realizará, de manera exclusiva las siguientes operaciones:

a. Recibir las aportaciones mensuales, semanales, quincenales u otros, de los socios.

b. Otorgar préstamos a los socios.

\section{Título VI}


De los ahorros

Art. 17. El socio hará un ahorro mínimo mensual obligatorio equivalente al 2 por ciento del Salario Basico General, depositado en la carta de pago del Consumo De Agua Potable.

Art. 18. En caso de que el socio tenga crédito, podrá retirar la parte proporcional excedente de sus ahorros, únicamente después de haber cancelado el 50 por ciento de su préstamo.

Art. 20. Cuando el deudor no haya cubierto su crédito en el tiempo estipulado, el socio garante no podrá retirar sus ahorros de conformidad con lo estipulado en el Art. 18 del Reglamento.

Art. 20. El socio que solicitare la liquidación de sus ahorros será atendido en el plazo máximo de 30 días, salvo lo estipulado en el art. 19, de este Reglamento.

\section{Título VII}

\section{De los préstamos}

Art. 21. Los préstamos se otorgarán a los socios que tuvieren por lo menos 6 meses de imposiciones y no serán superiores al triple de lo que tiene ahorrado. Además, deben estar al día en sus pagos con la Asociación.

Art. 22. El plazo para cancelar los préstamos será de 12 meses a partir de la fecha de otorgamiento y se cancelara en mensualidades proporcionales y consecutivas que serán depositadas en la Tesorería de la Caja común Espíritu Santo de Celen.

Art. 23. El prestatario, al hacer efectivo el préstamo, suscribirá un $10 \%$ a la orden de la Caja común Espíritu Santo de Celen, conjuntamente con un garante que debe ser miembro de la Asociación, por el total de la suma prestada y sus intereses. El garante no deberá ser miembro de la Comisión Ejecutiva de Crédito.

Art. 24. En caso de incumplimiento de lo dispuesto en el Art. 22, se procederá a hacer el traspaso de sus ahorros en la cantidad respectiva para cancelar la cuota mensual que le corresponde.

Art. 25. En caso de que el prestatario dejase de ser socio, la deuda será cancelada con sus ahorros, y, en caso de que no le alcancen, se notificará al garante, para dar cumplimiento al Art. 19 del Reglamento.

Art. 26. La solicitud de préstamo será dirigida al Presidente de la Caja mediante una solicitud, que especifique plazo y monto, para su trámite respectivo. La petición será aprobada por la Comisión Ejecutiva de Crédito en la primera sesión que tuviere y despachada dentro de las 24 horas, a raíz de su aprobación.

Art. 27. Para tener opción a un nuevo préstamo debe haberse cancelado por lo menos el $50 \%$ por ciento del préstamo anterior.

\section{Título VIII}




\section{De los intereses}

Art. 28. Los intereses serán prorrateados proporcionalmente con la cuota mensual del crédito, sobre el saldo deudor.

Art. 29. El interés por mora será del 2 por ciento sobre la cuota vencida.

Art. 30. Los intereses por ahorro se percibirán semestralmente, y los mismos serán capitalizados automáticamente en los ahorros, o retirados según sea la voluntad del socio.

Disposición Transitoria

Art. 31. Todos los créditos concedidos con anterioridad a la vigencia de este Normativa se cancelarán de acuerdo con la praxis dada.

Loja, enero del 2017

Aprobada por la Asamblea en sesión del día

La Comisión de Crédito

Gerente

Se puede crear un reglamento de ahorros y un reglamento de préstamos para establecer lineamentos claros y tengan un efectivo cumplimiento

INFORMACIÓN DEL SOCIO

NOMBRES Y APLELLIDOS

CODIGO DEL AFILIADO IDENTIDAD TELEFONO CELULAR

LUGAR D ETRABAJO TELEFONO DEL TRABAJO

Elaboración: La Autora

INFORMACIÓN DEL GARANTE

NOMBRES Y APLELLIDOS

CODIGO DEL AFILIADO IDENTIDAD TELEFONO CELULAR

LUGAR D ETRABAJO TELEFONO DEL TRABAJO 


\section{Elaboración: La Autora}

¿Qué cargos existen dentro de la Caja?

(Tortosa, 2015). Los cargos Creados para la Administración de la Caja, pueden ser administrativos y operativos, en el caso de las comunidades rurales son el presidente, secretario, tesorero, comité de crédito, consejo de Administración y el consejo de vigilancia.

La Mesa Directiva permite, a sus participantes, desarrollar sus capacidades. En la presidencia, se aprende a gestionar y a realizar vínculos con otras organizaciones, servicios públicos o privados para ampliar las oportunidades de la Caja. En la tesorería se aprende contabilidad y finanzas, conocimientos que también se pueden aplicar en la vida diaria. En la secretaría, se aprende a reunir y ordenar información, tanto de los socios como de la Asamblea.

Por su parte, el trabajo de la Junta de Vigilancia asegura que el dinero de los socios no va a ser usado en actividades que la Asamblea pueda rechazar (como compra de alcohol o drogas). Esto es por una razón práctica: si el préstamo no se utiliza para algún fin productivo, es muy probable que no pueda ser devuelto. Los cargos tanto en la Mesa Directiva como en la Junta de Vigilancia, sean repartidos equitativamente entre hombres y mujeres.

¿Cómo funciona la Asamblea?

(Cañabate, 2003), La máxima autoridad de la caja, se encarga de la duración y de la regularidad de las sesiones, convocatoria y agenda

- Se encargará de la elección de los miembros del consejo de vigilancia

- Se encarga de la toma de decisiones

- Derechos y obligaciones

- Tramite de solicitudes de préstamos

- Acta anterior

- Informe de actividades

Cómo funciona la caja común

(Garcia Roa, 2013) y Cristina Rentería Garita Quien requiere un préstamo se contacta con la presidenta (e) de la caja común,

- La presidenta o presidente comunica al tesorero

- El tesorero avisa al comité de vigilancia, que revisa su historial crediticio del solicitante y aprueba

El solicitante presenta la documentación a la secretaria

- Una vez aprobado la asamblea es quien entrega el dinero al solicitante

- La junta de vigilancia se asegura que el dinero sea entregado al beneficiario y no se utilice para otros fines. 


\section{Metodología}

Investigación, es cualitativa, que se fundamentó en descripción de las cajas comunales desde su creación, sus aportes y algunas contrariedades y la investigación es cuantitativa, ya que se pudo aplicar encuestas de satisfacción, para conocer de cerca si se cumplió con las expectativas d capacitación, hasta lograr la conformación de la caja común.

Se utilizó la técnica de la observación directa, una vez en el sector se aplicó fichas de recolección de información individual a cada uno de los moradores del sector para conocer de cerca las principales necesidades de la comunidad para de esta manera poder contribuir con una alternativa de solución, información; se requirió de información bibliográfica que respalda principales conceptos a utilizarse en la capacitación,

\section{Resultados}

A continuación, se evidencia el trabajo realizado con la comunidad de Celen en temas de capacitación para la creación de una caja común.

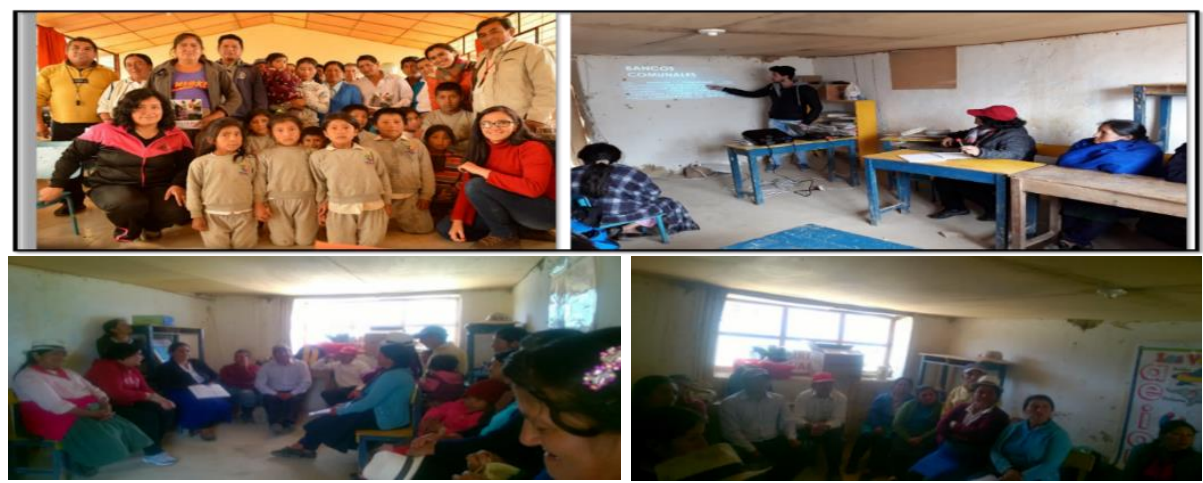

Imagen 1, socialización del proyecto y capacitación a la comunidad

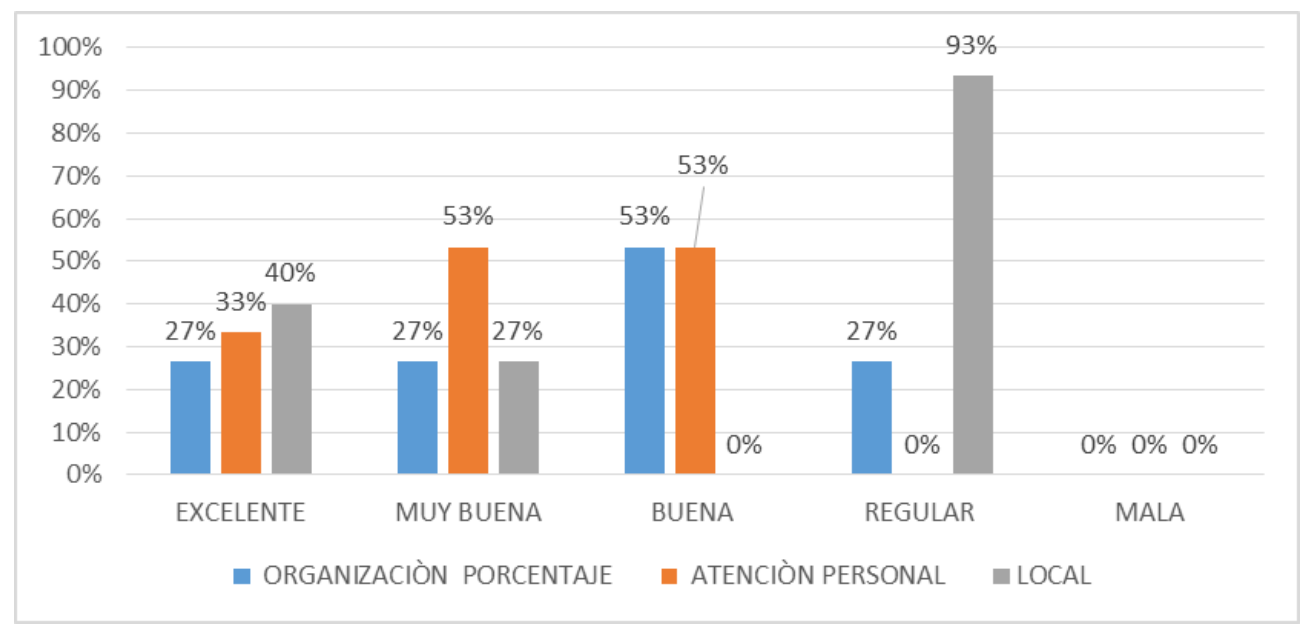

Gráfica 1. Evaluación Logística

Elaboración: Autora.

Análisis e interpretación de los resultados 
Los resultados de la encuesta aplicado a los beneficiarios de la capacitación, indican que el lugar en donde se llevó a cabo la capacitación no cumplió con sus expectativas, mientras que en la organización y atención del personal docente y estudiantes de la carrera de Fianzas se pudo aportar a su conocimiento en un $47 \%$ con un resultado bueno, en un $29 \%$ con un resultado muy bueno y un $12 \%$ con un resultado excelente. En cuanto a la organización de la capacitación les pareció buena en un $47 \%$, un $29 \%$ muy bueno y un $5 \%$ con un resultado excelente.

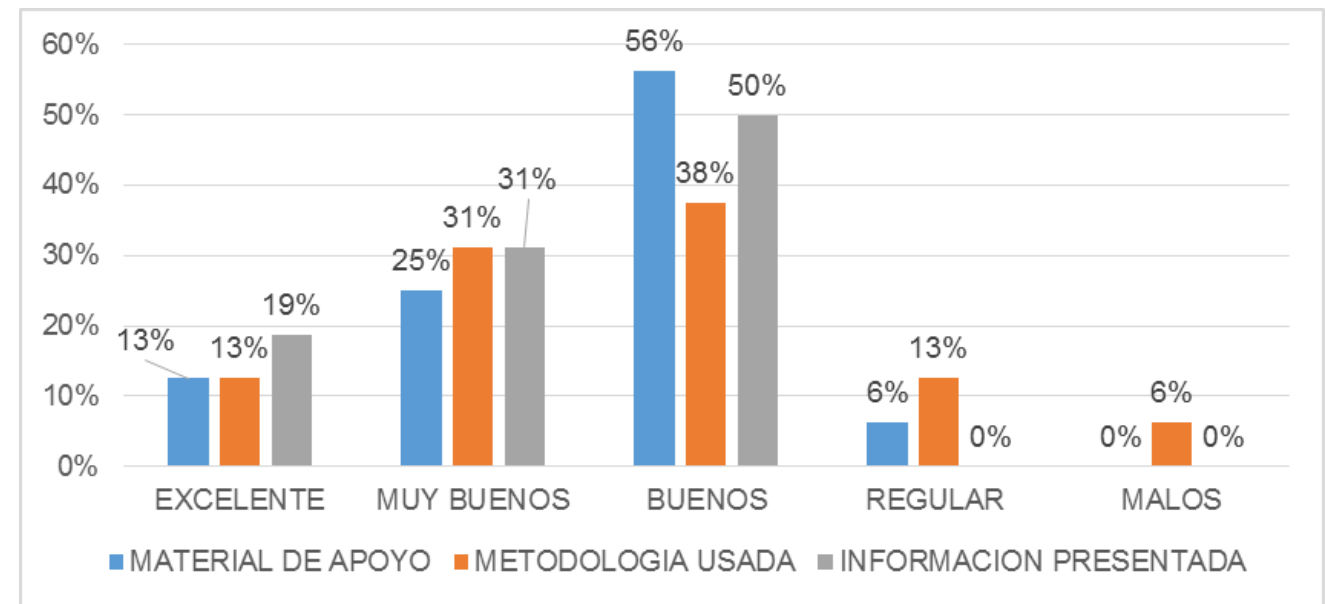

Gráfica 2. Evaluación de contenidos

Elaboración: Autora.

Análisis e interpretación de los resultados

El 56\% de los encuestados manifiesta su conformidad por los contenidos tratados en la capacitaciòn, el 50\% de los encuestados manifiestan que la información ha sido buena, así mismo al $37 \%$ de los encuestados les ha parecido buena la metodología empleada.

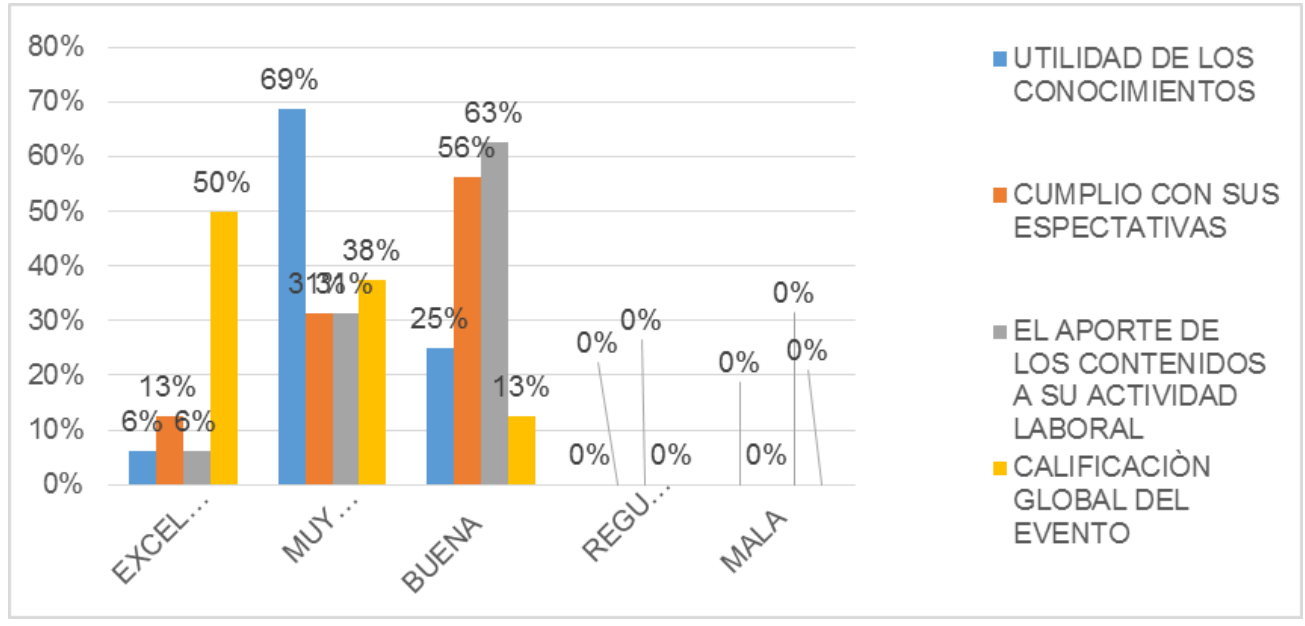

Gráfica 3. Evaluación del Evento

Elaboración: Autora.

Análisis e interpretación de los resultados 
En cuanto a la utilidad de los conocimientos el $69 \%$ manifiesta como muy buena la utilidad de los conocimientos, el $63 \%$ considero un importante aporte a la actividad que ellos realizan, el $56 \%$ considera que fue bueno en cuanto a sus respectivas. Y el $81 \%$ finalmente manifiesta una conformidad con el evento y los temas tratados, ya que los consideraron de utilidad.

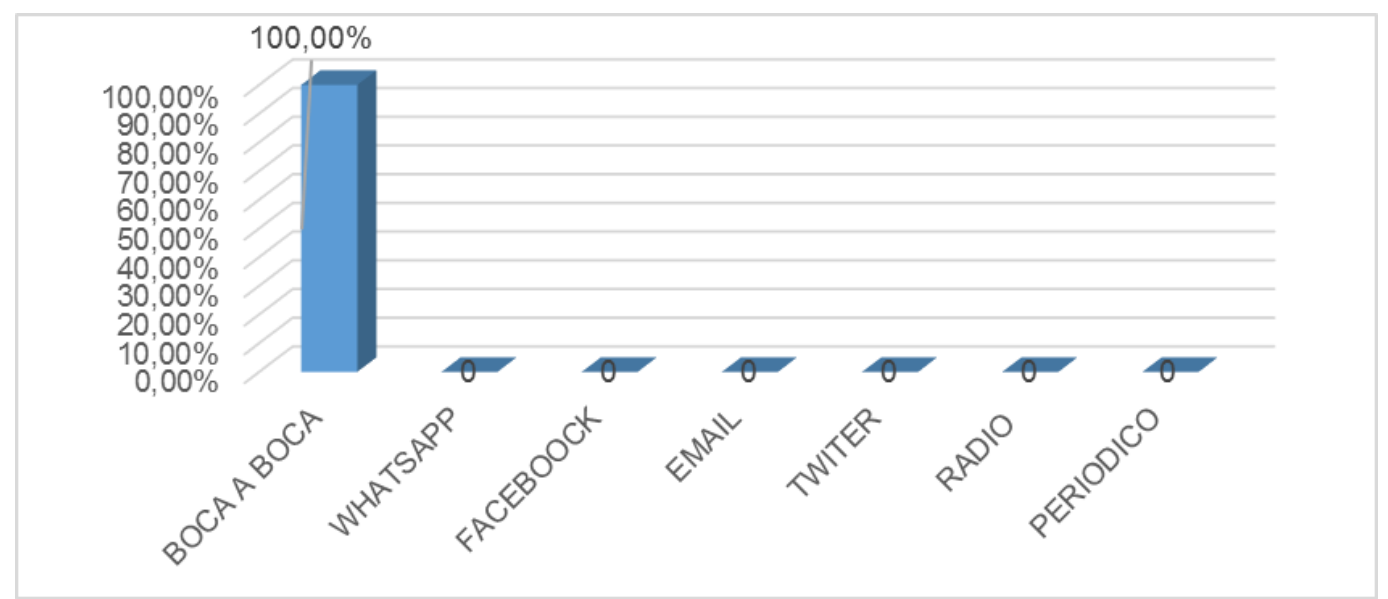

Gráfica 4. Evaluación del proyecto

Elaboración: Autora.

Análisis e interpretación de los resultados

En cuanto a los medios por el los cuales conoció del proyecto de capacitaciòn, el100\% de las personas encuestadas manifiestan haberse enterado por el voca a voca de los moradores de la comunidad.

\section{Discusión}

Los resultados obtenidos reflejan la conformidad por parte de los beneficiaros de la capacitaciòn, lo cual resulta beneficioso a las actividades productivas que ellos realizan. La capacitaciòn dio lugar a la conformación de la caja común denominada espíritu Santo de Celen, la misma que se conformó con un capital social inicial de $\$ 167,00$, el mismo que se creó, con el aporte de todos los socios, que dio un total de 16 personas. La caja común por desconfianza de los propios moradores desapareció, por no poder contar con un apoyo permanente de estudiantes y docentes de la universidad Internacional del Ecuador extensión Loja.

\section{Conclusiones}

Gracias al servicio que ofrecen las Cajas de Ahorro y Crédito al servicio de los perfiles más bajos de la sociedad, como carrera de finanzas se ha creído conveniente elaborar ésta propuesta de guía de capacitación para la creación de una caja común, en donde se integren los capitales de producción y se cuente con recursos financieros permanentes especialmente en tiempos de austeros. (Arnajo, 2005)

Reconocer la importancia creación de cajas comunes en los sectores vulnerables de la economía, ya que beneficiaría no solo a los de la comunidad, sino también a sectores aledaños, 
ofreciendo una ayuda financiera al alcance de todos. La capacitación dio como resultado la conformación de una caja común denominada Espíritu Santo de Celen. El capital inicial fue de $\$ 167,00$, con el aporte de todos los socios fundadores de la caja, producto de sus actividades productivas. Una caja común ayuda a la integración de capitales de producción y puedan contar con recursos financieros que promuevan el Ahorro, la Inversión y el financiamiento.

\section{Bibliografía}

Arnajo, J. M. (2005). Manual de Coopertaivismo y Economia Solidaria. Colombia: Universidad Cooperativa de cOlombia.

Boletin SEPS . $\left(02\right.$ de 05 de 2017). Boletin $N^{o} 5$. Obtenido de http://www.seps.gob.ec/documents/20181/455927/Boleti\%CC\%81n+SEPS+N\%C2\%BA 005-02-03-2017.pdf/939e79f3-2907-46a9-b255-64f96197f898?version=1.0

Cañabate, P. R. (2003). La fusión de Cajas de Ahorros. Obtenido de https://books.google.com.ec/books?id=7UoOAQAAQBAJ\&pg=PA421\&dq=creaci\%C3 $\%$ B3n+de+una+caja+comun+de+ahorro+y+credito\&hl=es\&sa=X\&ved=0ahUKEwjQuc mbvdvcAhWDq1MKHR6NBOYQ6AEIJTAA\#v=onepage $\& q \& \mathrm{f}=$ false

CEPAL. (2011). Auge, Caida y Transformación de las cajs de Ahorro y Crédito españolas, lecciones para America Latina. Santiago de Chile: Sección de estudios y desarrollo .

Flores, M., \& Rello, F. (2002). Capital Social Rural. Mexico: Plaza \& Valdez.

Flores, M., \& Rello, F. (2002). Capital Social Rural. México: CEPAL.

Gaminde, E. E. (2017). La doctrina social cristiana y el cooperativismo vasco. Una alternativa para el cambio. Madrid: Dykinson.

Garcia Roa, J. (2013). Las cajs de Ahorro y crédito españolas.

Gutierrez Fernandez, M. (2013). Cuadernos de Economía y dirección de empresas. Cuadernos de Economía y dirección de empresas Vol. 16, 250 -258.

Miró Acedo, I., \& Fernández Montes, A. (2016). La economía social y solidaria en Barcelona. Barcelona: Montaber, ajuntaber Bacelona.

Morales, B. R. (2015). El dinero emocional . Bilbao: Desclee de Brower.

Oriol, M. (2011). El cártel español: Historia crítica de la reconquista económica de México y . Madrid- Españ: EKala.

Rello, F., \& Margarita Flores. (2002). Capital Social Rural. Mexico: Plaza \& Valdez.com.

Renteria, C., \& Alberto, P. (2014). Guía de creación de cajas Urbanas . Santiago: Oficina de intercambios de conocimientos e investigación FAO. 
Salgado, O. G. (s.f.). Aprenda a Cuidar su Dinero: El mundo de las finanzas a su alcance.

Tortosa, E. (2015). Fulgor y muerte de las Cajas de Ahorros. Valencia: Universidad de Valencia. 